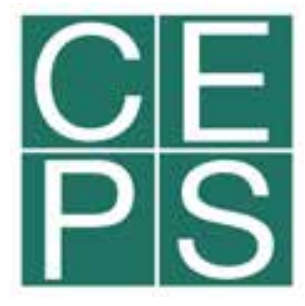

LABOUR MARKET RESPONSES TO THE COVID-19 CRIIIS IN THE UNITED STATES AND EUROPE

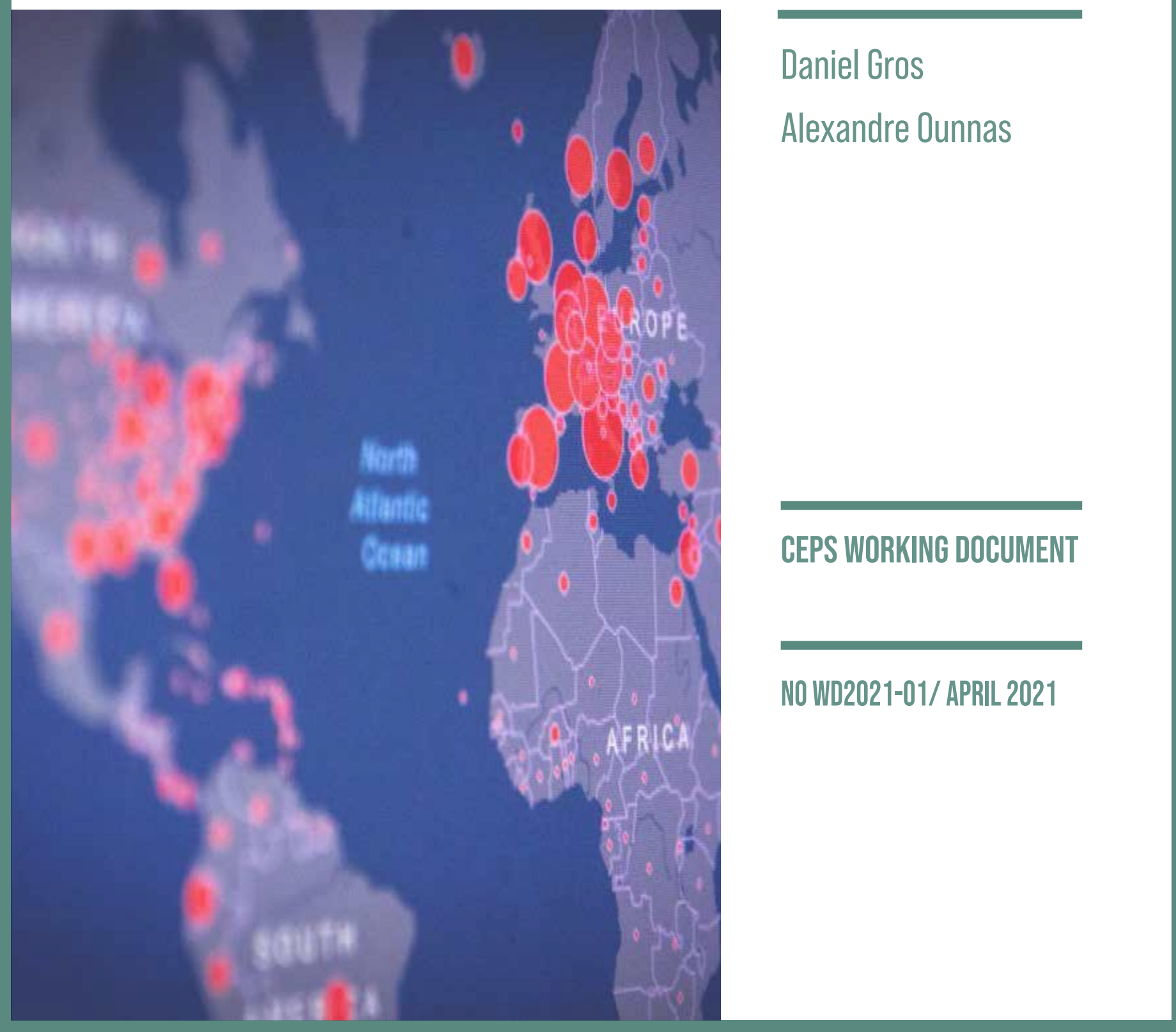




\title{
Labour market responses to the Covid-19 crisis in the United States and Europe
}

\author{
Daniel Gros and Alexandre Ounnas
}

CEPS Working Document No. 2021-01, April 2021

\begin{abstract}
Labour markets have reacted very differently to the Covid-19 crisis. In the US, the impact on unemployment rates was rapid across all states. They increased sharply in March and April 2020 and recovered steadily thereafter. In Europe, by contrast, unemployment increased far less, and the adjustment was more gradual.

This difference in unemployment responsiveness is most likely a consequence of the widespread use of short-term work schemes in Europe, given that the transatlantic differences in hours worked overall are much smaller than for unemployment.

Using data from US states and EU member states, an econometric analysis of the impact of the restrictions (lockdowns) implemented by governments to contain the spread of the virus reveals that in the case of the US, unemployment appears to have been driven mostly by the aggregate shock generated by the pandemic as it played out between March and November 2020. In the EU, unemployment showed little variation. The Non-Pharmaceutical Interventions (NPIs) used in different US states and EU countries, as can be demonstrated through a regression analysis, did not always have significant effects on unemployment.
\end{abstract}

Daniel Gros is CEPS Distinguished Fellow and Alexandre Ounnas is a Researcher in the Job and Skills Unit at CEPS.

This research has received funding from the Horizon 2020 research and innovation programme of the EU under grant agreement No.101016233, H2020-SC1-PHE CORONAVIRUS-2020-2-RTD, PERISCOPE (Pan European Response to the Impacts of Covid-19 and future Pandemics and Epidemics).

CEPS Working Documents give an indication of work being done within CEPS' research programmes and aim to stimulate reactions from other experts in the field. The views expressed in this document are solely those of the authors and do not necessarily represent the official position of CEPS. 


\section{Contents}

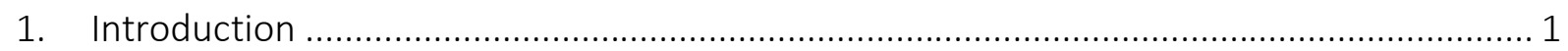

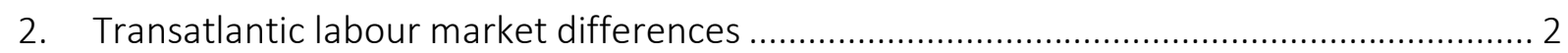

3. The Covid-19 shock for labour markets .......................................................................... 5

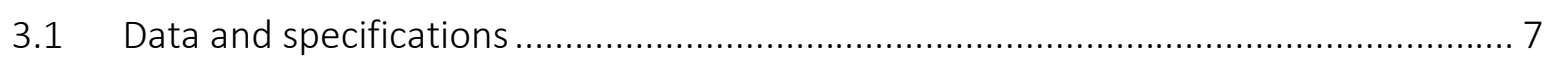

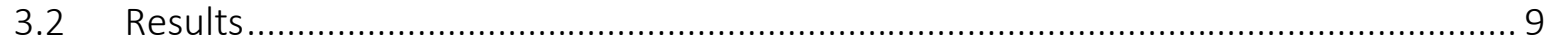

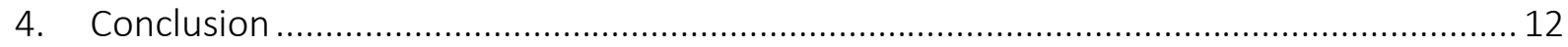

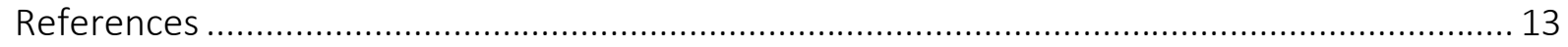

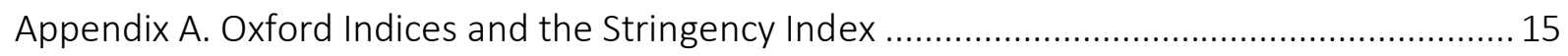

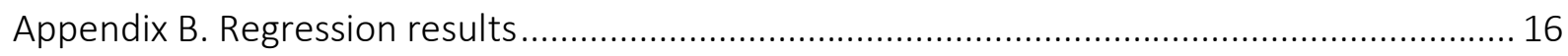

\section{List of Figures and Tables}

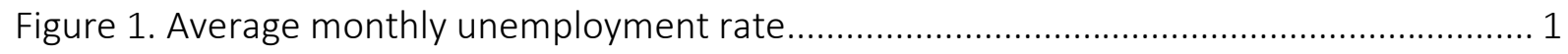

Figure 2. Employment, hours worked and GDP in the EU27 and the US during the 'Great

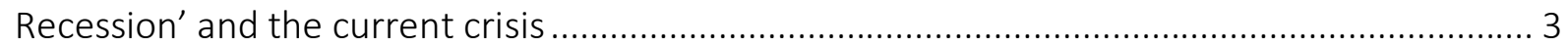

Figure 3. EU27 labour market slack, grouped by age cohort ................................................ 5

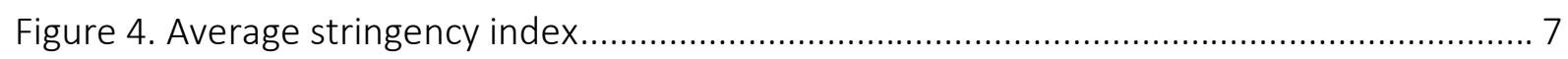

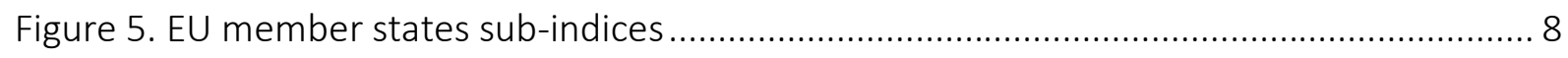

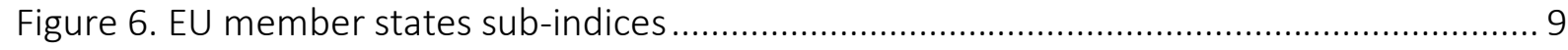

Figure 7. US states and EU member states time fixed effects ............................................. 11

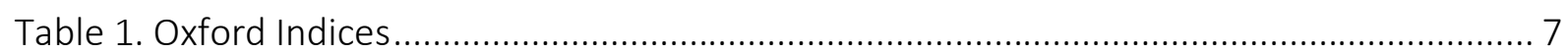




\section{Introduction}

It has been widely observed that in Europe, unemployment increased remarkably little, given the depth of the recession (a fall in GDP in excess of 10\% in many countries during the second quarter of 2020, and of $5 \%$ for the entire year). For the EU27, the average unemployment rate increased by less than 1.1 percentage points (from about 6.5\% to $7.6 \%$ at the end of the year). In the United States, swings in unemployment have been far sharper.

The US unemployment rate initially shot up by more than 10 percentage points (from below $4 \%$ in January to above $14 \%$ in April) and has since fallen to $7 \%$ in November. There is thus an order of magnitude difference in the short-term response of the unemployment rate.

These stark differences in the average rates are associated as well with substantial divergence within the United States and the EU. Most of the larger EU member states recorded increases in the unemployment rate of less than 1 percentage point (only in Italy did the unemployment rate increase by 3 points). In the United States the differences across individual states are much larger. In Nevada and Michigan, unemployment rates increased to 30.1\% and 24\%, respectively, in April, whereas the rise was more constrained in states like Minnesota or Connecticut (see Figure 1).

Figure 1. Average monthly unemployment rate

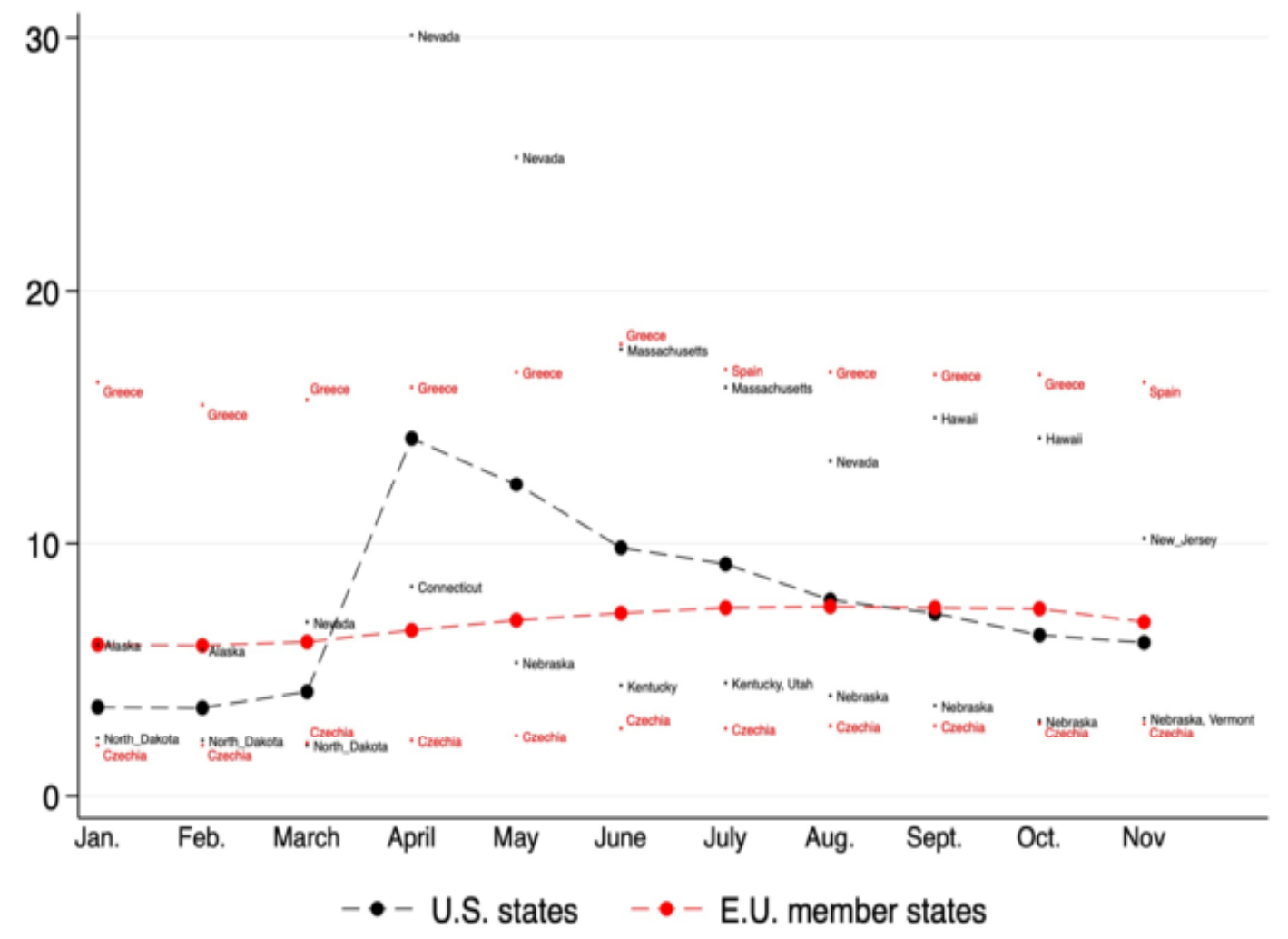

Source: Eurostat and Bureau of Labor Statistics.

Note: Average unemployment rate for the United States and the EU. In addition, the figure shows, for each period, the countries/states with the highest and lowest unemployment rates. 
Below we present a transatlantic comparison of unemployment rate fluctuations between March and November 2020 at the state/country level. We control for the impact of governmental containment measures (also called Non-Pharmaceutical Interventions, or NPIs) taken to limit the spread of Covid-19 as well as the severity of the pandemic, as proxied by the number of monthly cases and deaths. We exploit the considerable variations in measures taken among the 50 US states and the 27 member countries of the EU.

\section{Transatlantic labour market differences}

Before analysing the short-term impact of Covid-19 measures on unemployment, we want to provide an overall picture of how a strong recession affects labour markets in terms of employment versus hours worked (an indicator of labour hoarding, the practice of companies not laying off employees during a recession) and in terms of hours worked relative to GDP (an indicator of productivity).

Figure 2 shows the average area-wide data on total employment, total hours worked and GDP for the United States and the EU. ${ }^{1}$ The upper panel refers to the 'Great Recession' (2007-10), whereas the lower panel shows mainly the year 2020 (relative to 2019).

The first takeaway is that 2020 played out very differently from the 'Great Recession'. The fall in GDP was much sharper but the recovery almost immediate (a V-shaped recovery), as shown in the right-hand chart of the lower panel. The same applies to hours worked, which tanked in the second quarter of 2020 but started to recover immediately in Q3. In 2008-09, by contrast, it took several quarters to reach the trough, and the recovery was also more gradual.

One difference that emerges here is that in the United States, the fall in GDP is smaller than the fall in hours worked. Average productivity thus increased. This is most likely attributable to a labour market composition effect since many of the workers whose hours were lost were in low-productivity sectors. This composition effect shares some similarities with the so-called cleansing effect of recessions (Caballero and Hammour, 1994). Something similar happened in the United States in 2009-10 as well. On the other hand, in the EU, GDP fell by more than hours worked, implying a deterioration in productivity.

The pro-cyclicality of labour productivity can be explained by labour hoarding due to high firing \hiring \training costs, which limits the possibility for employers to adjust the size of their workforce as output decreases. An alternative explanation is the 'sullying effect' of recession (Barlevy, 2002)): Labour market churn (job-to-job transitions in particular) allows for a better match between employers and workers, and these labour market flows tend to decrease during recessions. Both the American and the European economies are likely to be affected by these mechanisms, and the cyclicality of labour productivity takes its shape from which effect

\footnotetext{
1 For the EU27, we use data on employment and hours worked computed from national accounts (https://ec.europa.eu/eurostat/Employment statistics within national accounts). For the United States, we use data published by the Bureau of Labor Statistics (https://www.bls.gov/lpc/tables).
} 
dominates the others. What remains is that recessions seem to provide a boost to (hourly) productivity in the United States but not in Europe.

Figure 2. Employment, hours worked and GDP in the EU27 and the US during the 'Great Recession' and the current crisis
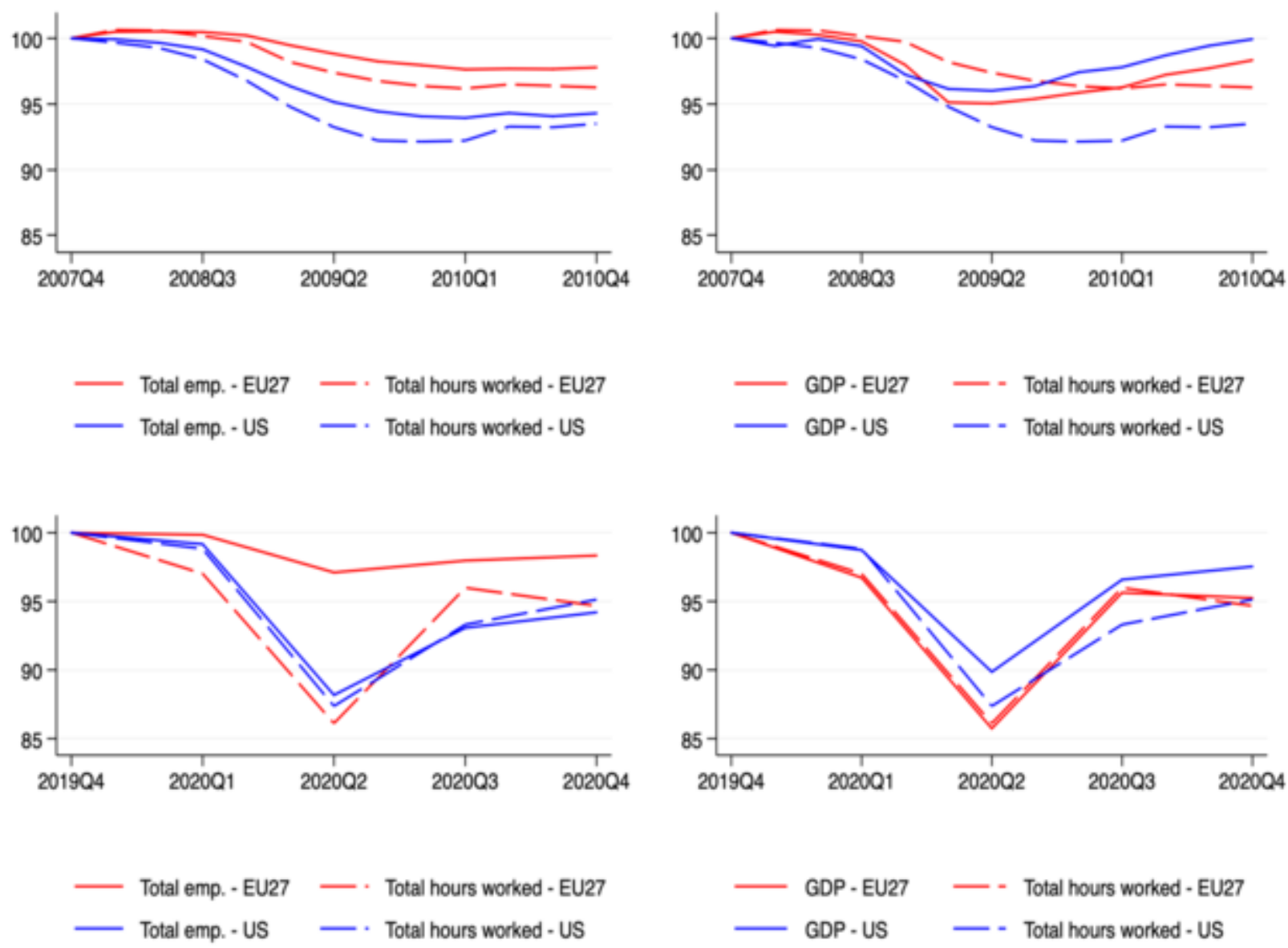

Source: Eurostat and Bureau of Labor Statistics.

Note: Each variable is seasonally adjusted and expressed as an index with a reference period of Q4 of 2007 and Q4 of 2019, respectively.

A second major difference emerges from the left-hand chart of the lower panel. For the United States, employment and hours worked are almost indistinguishable. This means that few American workers were put on short-time arrangements, and the hours lost were almost exclusively because of firings or layoffs. In the EU, by contrast, hours worked fell by as much as in the United States (close to 15\%), but employment barely budged (a fall of about 3\%). Hours worked have recovered strongly in the EU as well, and their overall decline is now much more in line with the drop in employment. Hence, short-term work (STW) schemes seemingly had the intended impact: most workers were able to keep their job but worked fewer hours for a limited period. 
This pattern contrasts somewhat with that observed during the 2008 crisis, during which only a limited number of EU countries (e.g., Germany, Italy) had set up STW schemes. At that time, the recovery in hours took far longer and the difference between hours and employment was much smaller.

Before turning our focus to the effects of NPIs on unemployment, it is important to recognise that unemployment rates can hide a 'discouraged worker effect', that is, potential workers who stopped looking for jobs to wait for conditions to improve and economic sectors to reopen. For the EU, there is limited evidence of a discouraged worker effect, which can be gleaned from the labour market slack statistic ${ }^{2}$ displayed in Figure 3.

This statistic goes beyond the unemployment rate by summing unemployment, underemployment (individuals working part time and claiming they want a full-time job), workers seeking a job but not currently available and workers not seeking a job but available to work. The last two groups of individuals are excluded from the labour force and considered inactive. Labour market slack is therefore expressed as the sum of all unmet labour supply among the four groups mentioned above as a percentage of the extended labour force (ELF = the labour force + the two groups not counted as part of the labour force). An increase in the percentage of individuals currently not seeking a job but available to work during 2020 likely points to a discouraged worker ${ }^{3}$ effect over the year.

Between the last quarter of 2019 and the second quarter of 2020, the share of potentially discouraged workers increased by 1.5 percentage points for individuals aged up to 74 years. In absolute terms the increase is small - as one would expect given the small fall in employment - but in relative terms it amounts to a $50 \%$ jump (rising from $3 \%$ to $4.5 \%$ of the ELF). Moreover, the surge is highest for young workers. This worsening of labour market conditions for some segments of the labour force was partially reversed during the third quarter.

Overall, labour markets have been surprisingly resilient in Europe: employment has fallen little in the face of a recession of unprecedented magnitude.

\footnotetext{
2 See Eurostat/labour market slack for more detail.

${ }^{3}$ The exact definition for discouraged workers usually takes into account additional dimensions of individual job search history. For instance, see BLS/discouraged workers for the BLS definition.
} 
Figure 3. EU27 labour market slack, grouped by age cohort

$15-24$

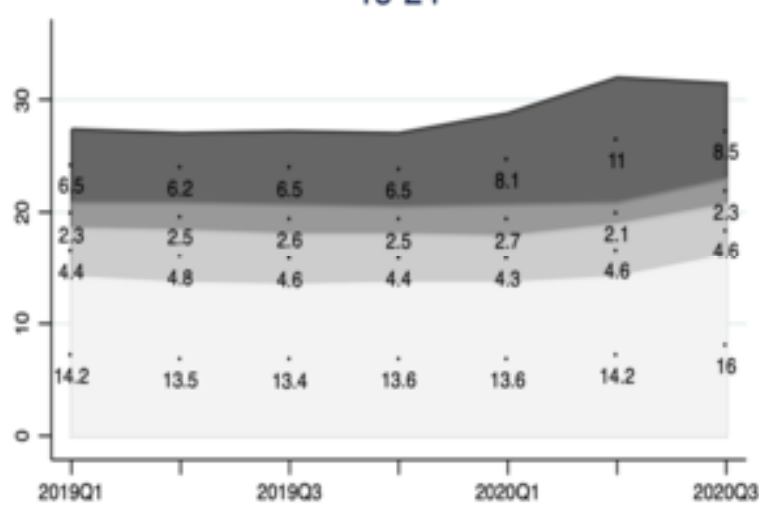

$55-74$

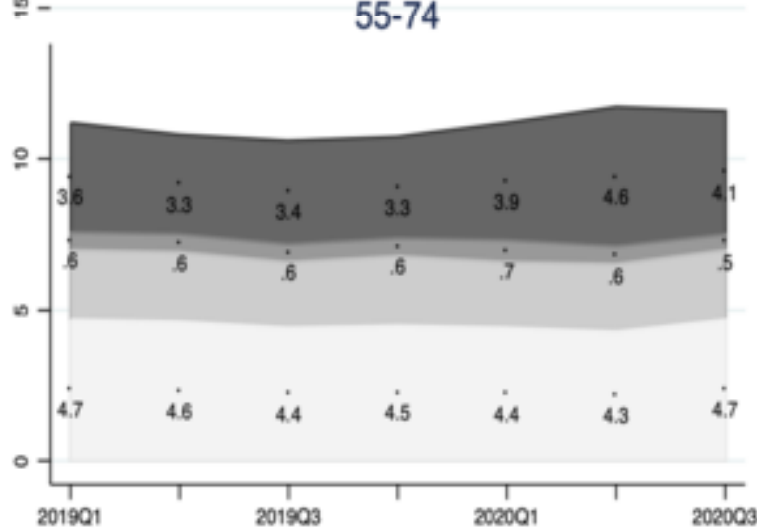

25-54

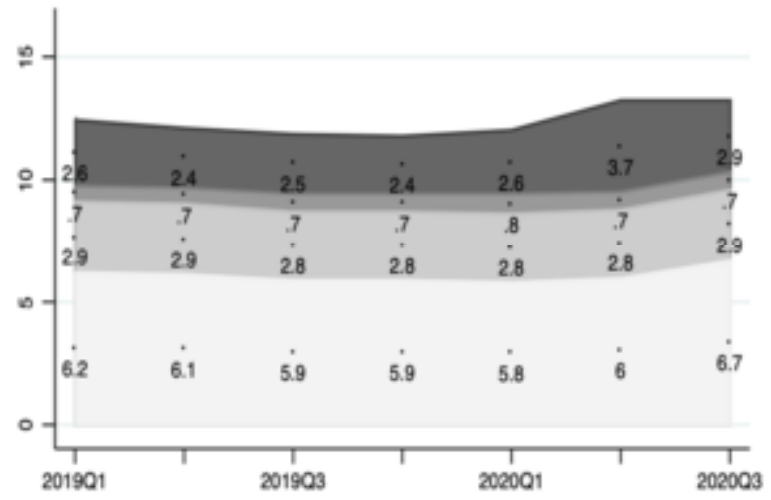

$15-74$

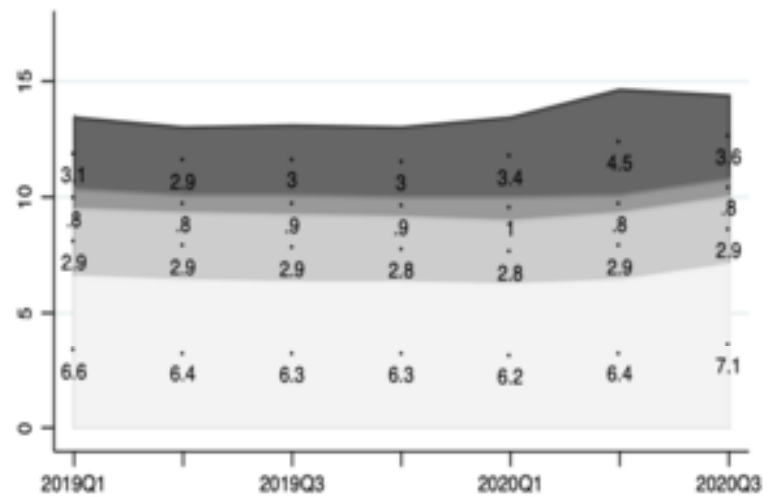

Unemployment

Under-employment

Seeking not avail.

Not seeking avail.

Source: Eurostat.

\section{The Covid-19 shock for labour markets}

There already exists a substantial literature ${ }^{4}$ documenting the effects of the Covid-19 economic crisis on the labour market (Forsythe et al., 2020; Fernández-Villaverde and Jones, 2020; Fana et al., 2020) focusing mainly on the United States. It reports considerable effects on employment in sectors that, by their nature, cannot readily implement social distancing measures (e.g., restaurants, accommodations). Sectors deemed essential (healthcare, education) for which teleworking is easier to implement have suffered smaller employment losses. Furthermore, only part of this employment loss translated into higher unemployment figures because many workers actually dropped out of the labour force (Cowan, 2020). These impacts are found to affect both labour supply and demand, as the rate of new job vacancies

\footnotetext{
${ }^{4}$ See Brodeur et al. (2020) for a more exhaustive literature review of the economic and labour market effects of Covid-19.
} 
decreased substantially (Barrero et al., 2020; Kahn et al., 2020). Most of the contributions to the literature also highlight that customarily disadvantaged groups (racial minorities, less educated workers and women) appear to be more seriously affected by the adverse economic effects of the pandemic (Montenovo et al., 2020; Gezici and Ozay, 2020; Reichelt et al., 2020; Alon et al., 2020).

Another portion of the literature has been concerned with identifying the potential negative effects of NPIs on labour market outcomes. These studies usually take advantage of the considerable variations in the timing and the stringency of measures implemented across EU countries and US states. Mixed results are reported. Some argue that the severity of the outbreak generated a common (or aggregate) negative shock, accounting for most of the labour market effects (Chen et al., 2020; Rojas et al., 2020). These studies usually highlight that the states or countries most severely affected were those where the outbreak of the pandemic was larger (e.g., Spain, Italy, New York). They further emphasise the role of voluntary social distancing, whereby individuals adjusted their behaviour and demand before the implementation of NPIs. ${ }^{5}$ On the other hand, some studies (Kong and Prinz, 2020; Gupta et al., 2020; Juranek et al., 2020; Dreger and Gros, 2021) report a significant effect of business closures and stay-at-home orders. Amuedo-Dorantes et al. (2020) stress the effects of school closures on the labour supply of women.

These studies usually rely on data for the months of March and April 2020, capturing labour market effects at the onset of the outbreak, when restrictive measures were first implemented. Few analyses focus on the labour market recovery, when restrictions were loosened. ${ }^{6}$ Moreover, the significant time lag in the publication of official labour market statistics and the (relatively) low frequency with which these statistics are made available (the best being monthly), have forced researchers to use alternative indicators that can serve as proxies for labour market and economic activity. These are typically unemployment insurance claims, Google's mobility tracker, Google search indices or electricity consumption.

The remainder of this section aims to complement the above contributions, making use of the fact that our period of observation spans a full cycle of first tightening (primarily during the spring) and subsequent relaxation of NPIs. The monthly frequency of reports on unemployment rates and our use of aggregated data (by gender, sectors, etc.) limits our ability to uncover fully the effects of NPIs. Therefore, our focus is mostly on documenting the significant variances between the fluctuations of US states' and EU member states' unemployment rates.

\footnotetext{
${ }^{5}$ As pointed out by Fernández-Villaverde and Jones (2020), health awareness campaigns by government are likely influencing this voluntary behaviour.

${ }^{6}$ Dreger and Gros (2021) report significant differences between tightening and loosening periods of NPIs on US unemployment claims. Gallant et al. (2020) and Chodorow-Reich and Coglianese (2020) propose forecasts of the US labour market recovery using quantitative models and under a range of assumptions. However, they are not concerned with NPI effects on the labour market.
} 


\subsection{Data and specifications}

We use seasonally adjusted unemployment rates by US states and EU member states published, respectively, by the Bureau of Labor Statistics (BLS) and Eurostat. We further rely on the government response tracker developed by Oxford's Blavatnik School of Governance (Hale et al., 2020) as the key measure of restrictiveness of governmental response to Covid-19. This tracker provides a consistent categorisation of various policy responses taken by governments around the world. Table 1 displays the subcategories that we use to construct nine indices $\left(I_{1}\right.$ through /9) for our analysis and that are aggregated to build the Oxford stringency index. Some detail on these computations can be found in Appendix A. All these indices are available at a daily frequency, and we obtain monthly time series by computing daily averages. Figure 4 displays the average stringency index for the United States and the EU.

Table 1. Oxford Indices

\begin{tabular}{llc}
\hline Subcategories & Measure & $\min / \max$ \\
\hline$C 1$ & School closures & $0 / 3$ \\
$C 2$ & Working place closures & $0 / 3$ \\
$C 3$ & Cancel public events & $0 / 2$ \\
$C 4$ & Restrictions on gatherings & $0 / 4$ \\
$C 5$ & Close public transport & $0 / 2$ \\
$C 6$ & Stay at home requirements & $0 / 3$ \\
$C 7$ & Restrictions on internal movements & $0 / 2$ \\
$C 8$ & International travel controls & $0 / 4$ \\
$H 1$ & Public information campaigns & $0 / 2$ \\
& & \\
\hline
\end{tabular}

Figure 4. Average stringency index

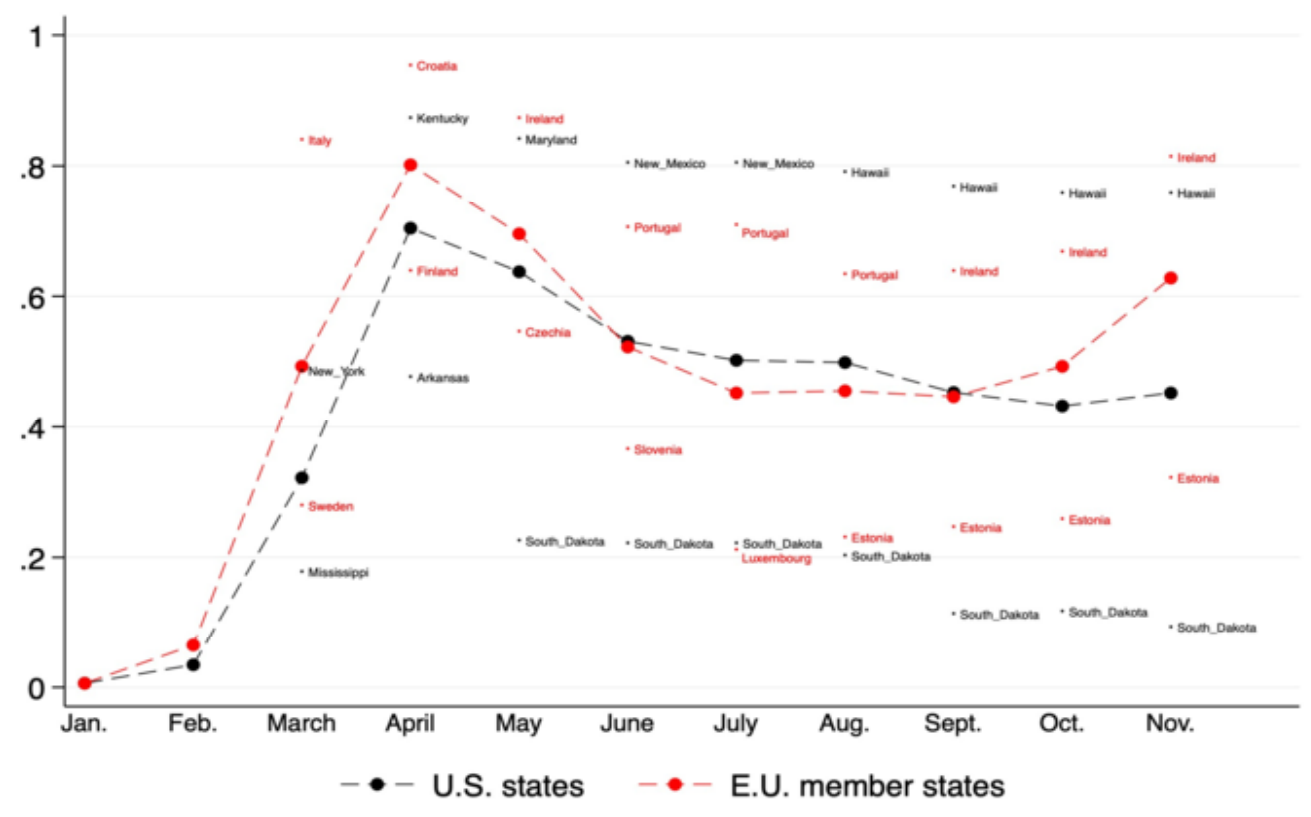

Source: Oxford Blavatnik School of Governance government response tracker.

Note: Average stringency index for the United States and the EU. In addition, the figure shows, for each period, the countries/states with the minimum and maximum value of the stringency index. 
These indices are published separately for each country of the EU and, more important, for each of the 50 US states (plus Puerto Rico and the District of Columbia). The US federal government has little direct control over school closures, restrictions on public events or gatherings and local public transport. The decisions on most of these measures are taken in the state capitals, sometimes even at the local level. There has been considerable variability across US states in both the timing and the severity of the restrictions. This is highlighted in Figure 5, which displays each of the sub-indices presented in Table 1 for the states of California, Indiana, New York and Nevada. It is interesting to note that the heterogeneity among states' policy strategies appears most pronounced in the later months of the pandemic and concerns the loosening of NPIs and the subsequent response to the second wave of the pandemic. Therefore, it is important to consider the latter phase of the pandemic when working with monthly data. A similar picture emerges from Figure 6, which displays sub-indices for Denmark, France, Italy and Poland.

Figure 5. EU member states sub-indices
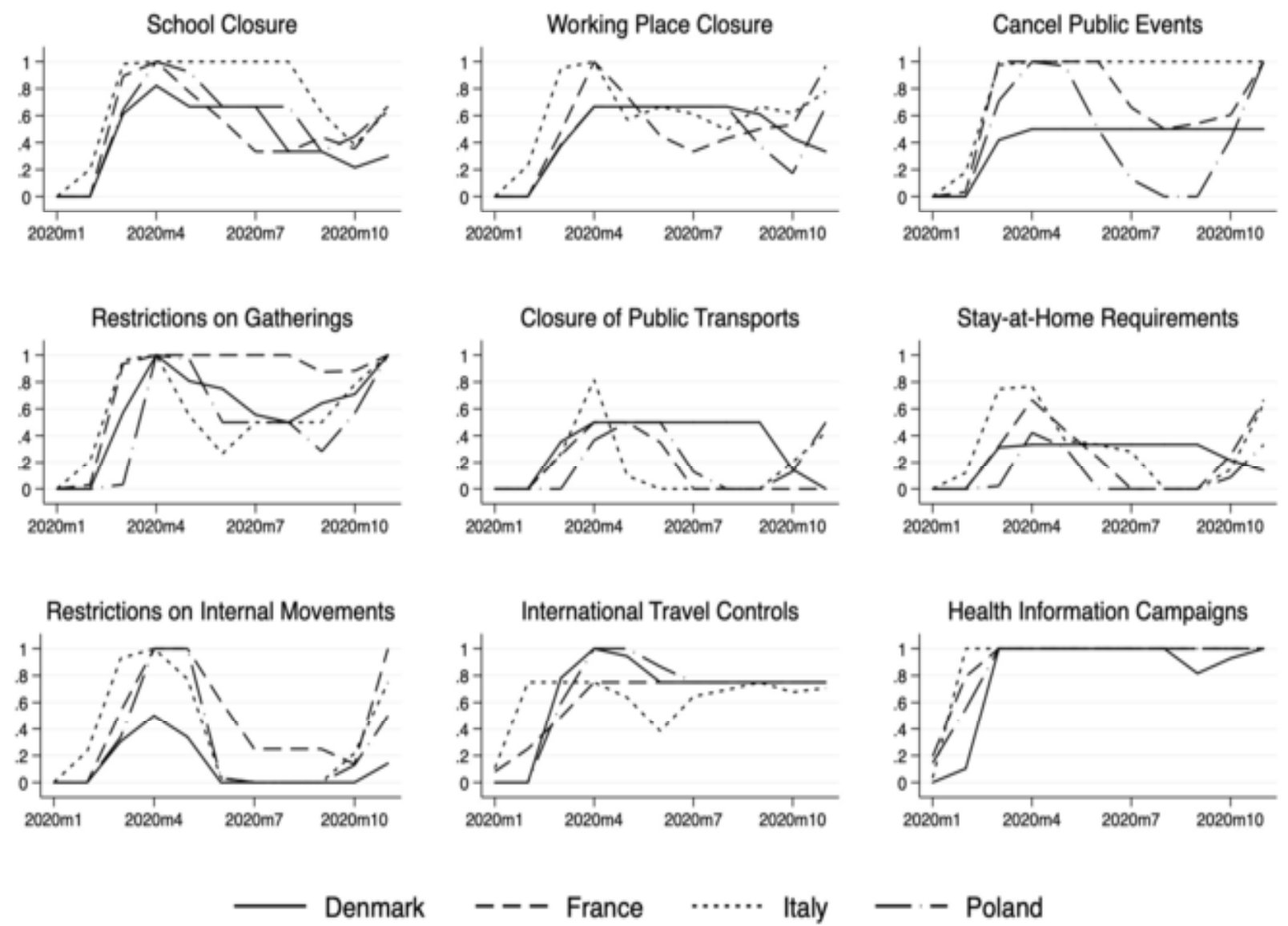

Source: Oxford Blavatnik School of Governance government response tracker. 
Figure 6. EU member states sub-indices
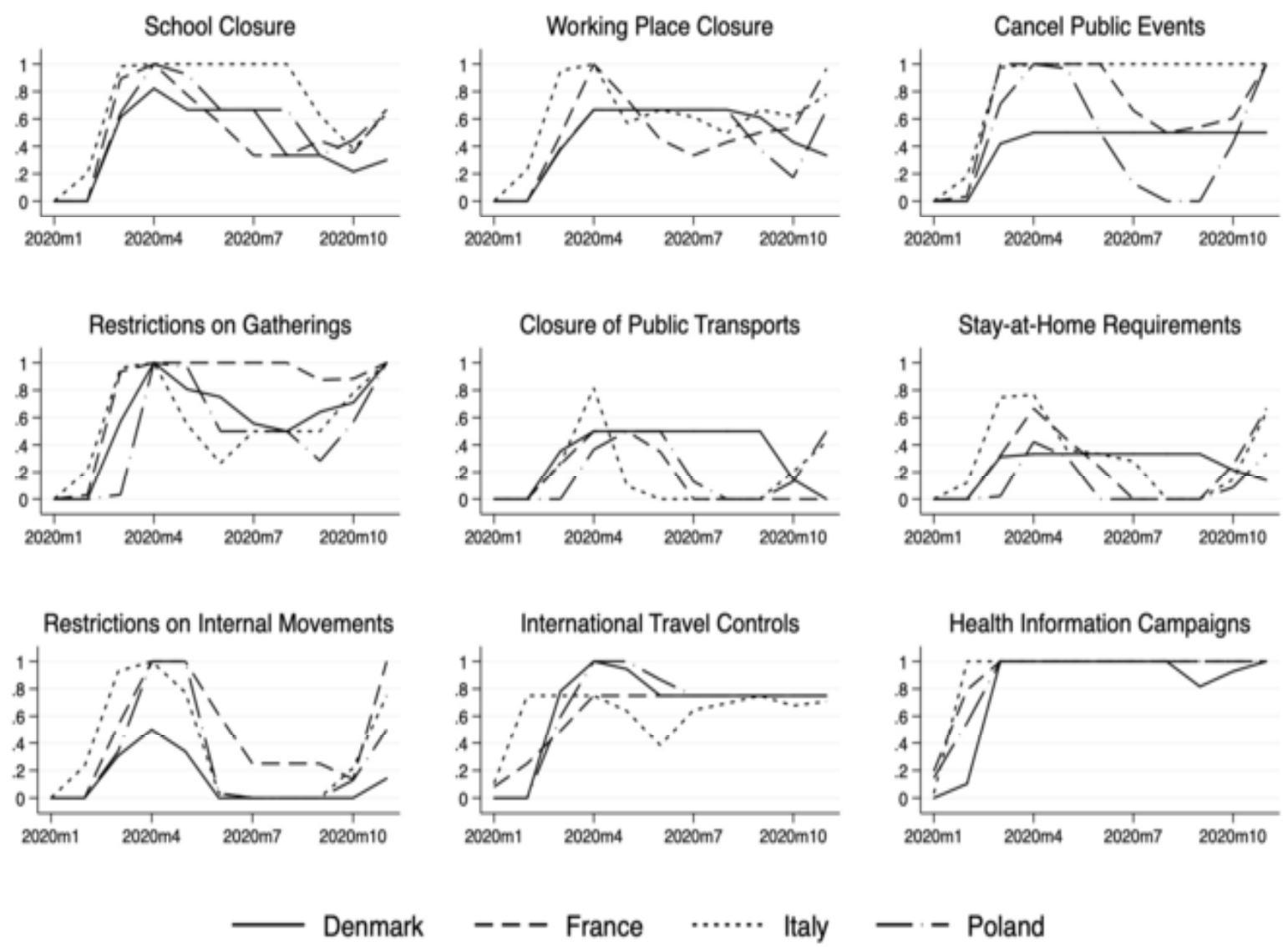

Source: Oxford Blavatnik School of Governance government response tracker.

\subsection{Results}

The monthly data gathered on the containment measures in various jurisdictions can then be combined with the standard monthly unemployment rate series, tracked for each US state and for individual European countries for the period February to November 2020, available from the BLS and Eurostat.

To discover the effects of these various policies, we analyse the unemployment rate, as the dependent variable, against the index of restrictiveness of NPIs, as the independent variable.

Given that both variables were influenced by a trend, we express all variables in first difference and regress the unemployment rate, $u_{i, t}$, for countries/states $(i)$ on index $j$ with two lags, $k, a$ set of countries/states fixed effects, $d_{i}$, and month fixed effects, $d_{t}$. We include the number of Covid-19 cases and deaths in log-difference as an additional control variable, $X_{i, t}$ :

$$
\Delta u_{i, t}=\sum_{k=0}^{2} \delta_{k} \Delta I_{j, t-k}+d_{i}+d_{t}+\beta X_{i, t}+\varepsilon_{i, t}
$$


The countries/states fixed effects represent the variations in unemployment rates specific to each country or state (if any), which are held constant over the sample period. On the other hand, the monthly time fixed effects capture the fluctuations in unemployment rates for each separate month for all countries/states throughout the sample period. It is usually complicated to interpret such fixed effects since many events or considerations could have impacts on these variables. For the time fixed effects, however, we argue that they are likely to capture the aggregate effect of the pandemic on unemployment rates. Firstly, we use seasonally adjusted data so that all potential monthly variations coming from seasonal concerns should be accounted for. Secondly, we restrict the sample period to February-November 2020 (taking February as the reference month), and the main aggregate economic driver over this period has been the pandemic. The policy responses of US state or EU national government authorities are also shaping the economy over this specific period, but we try to control for these using the Oxford indices. Thus, when analysing the results, we contrast the time fixed effects with the Oxford indices coefficients, as they represent an aggregation of the specific state/country government responses to limit the spread of the virus. ${ }^{7}$

We performed a total of 10 regressions (nine sub-indices $l_{j}$ and the overall stringency index), each for the United States (50 states and the District of Columbia) and Europe (23 EU member states ${ }^{8}$ ). We do not include unemployment rate lags in the regression equation (1) to avoid endogeneity problems and having to resort to more advanced estimation techniques. Hence, the results displayed in Table 2 in the Appendix should be seen as exploratory.

The results show that NPIs were found to have no significant effects on monthly unemployment rate fluctuations in either the United States or the EU. School closures appear to have a positive effect on unemployment in both regressions, but the coefficients are not precisely estimated.

On the other hand, the estimated time fixed effects displayed in Figure 7 tend to be statistically significant, which suggests that unemployment fluctuations in the United States and the EU were driven in each case by negative economic shocks generated by the Covid-19 pandemic.

The time fixed effects in Figure 7 illustrate a striking difference of the unemployment rate performance over the year between the two economies. In the United States, the point estimate of time fixed effects for April is large and statistically significant, followed by negative coefficients from May onward (with significant coefficients in June, July and August). This pattern matches the large increase and subsequent decrease in the US unemployment rate displayed in Figure 1.

\footnotetext{
${ }^{7}$ We do not attach too much importance to country/state fixed effects, given that only the coefficient for Lithuania is statistically significant. This result can be explained by unemployment rates having recovered their February level in the United States and having barely increased in many European countries. As such, the state fixed effects are included mostly to ensure that the estimated residuals have 0 means.

8 Unemployment figures were not yet available for Estonia, Greece, Hungary and Malta for the month of November. As a result, we dropped these four countries from our sample.
} 
Figure 7. US states and EU member states time fixed effects

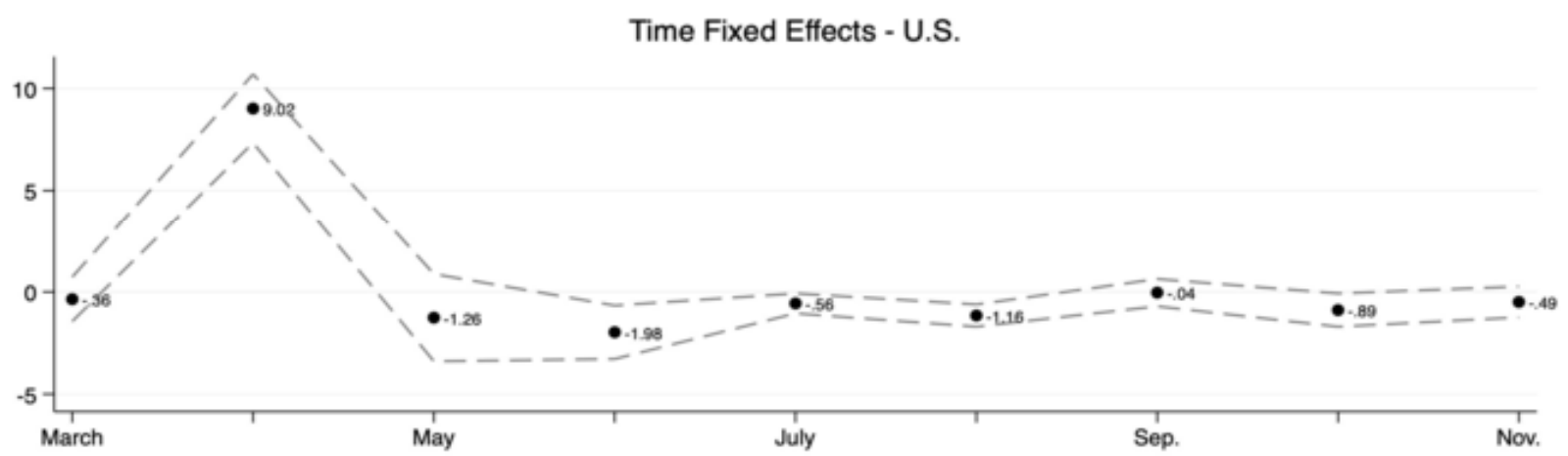

Time Fixed Effects - E.U.

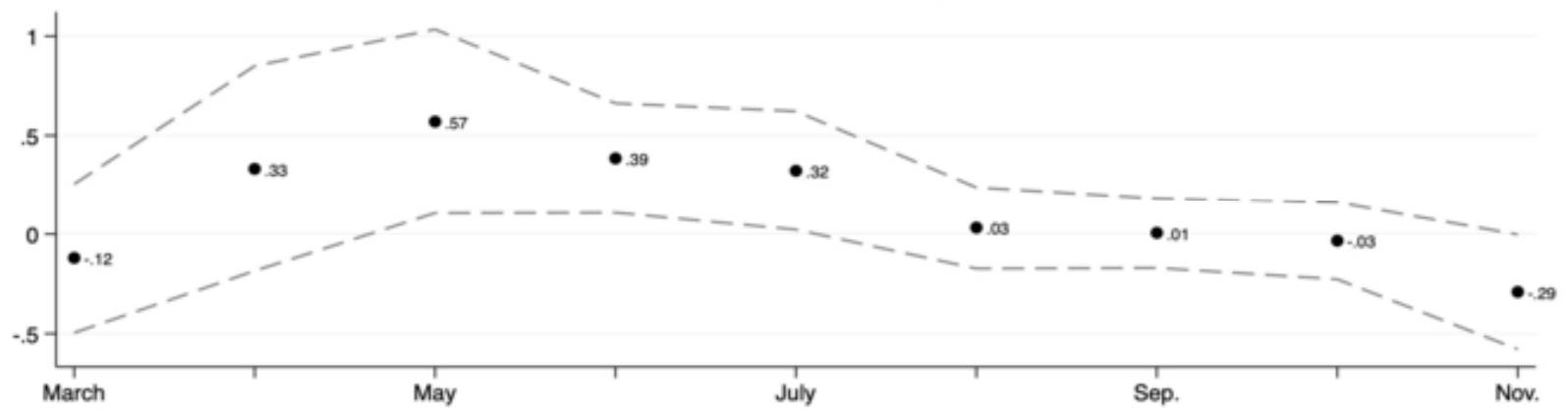

Source: Authors' own computations.

Note: Estimated time fixed effects for the United States and the EU using school closures as independent variables. February is taken as the reference month. The $95 \%$ confidence bounds are displayed as grey dashes.

For the EU, the estimates are much smaller than those reported for the United States (around 20 times smaller in April). Nonetheless, they remain positive and statistically different from zero until July. These observations are again consistent with the evidence of Figure 1 and highlight the much smaller and more sluggish adjustment of unemployment in EU member states.

The difference in the size and dynamics of the fixed effects likely originates from the widespread use of STW schemes in Europe. ${ }^{9}$ STW arrangements allow firms to reduce hours without laying off staff and compensate workers for the loss of income through government transfers (Cahuc, 2019), an effect consistent with the evidence reported and discussed in Section 2.

However, it is important to acknowledge that the use of monthly aggregated data by age, gender or sectors makes it difficult to isolate the actual effect of NPIs and to compare their effects across the EU and the United States. Furthermore, it is likely that the economic shock of the pandemic and the effects of NPIs drove some job seekers out of the labour force, which tempered the increase in the unemployment rate (see also Section 2). Amuedo-Dorantes et al.

${ }^{9}$ See https://www.etuc.org for a compilation of the various schemes used by EU member states. 
(2020) provide support for this argument by pointing out the negative effect of school closures on the participation rate of women.

\section{Conclusion}

We have documented a fundamental difference in performance between of economies on either side of the Atlantic. In the United States, the unemployment rate was subject to wide swings. A sharp increase in March and April 2020 was followed by a quick recovery from May onward. In Europe, by contrast, the unemployment rate adjustments have been far more subtle. The collective rate increased to a much lesser extent in March and April, but the recovery was also more prolonged than was observed in the United States.

The milder increase in the EU unemployment rate translates into a much smaller decrease in employment overall. However, total hours worked track the course of GDP, with a substantial decrease during the second quarter of 2020 followed by a recovery in the third quarter. The absence of such dynamic in the United States suggests that the widespread use of short-term work provisions has isolated the European labour market from the large swings in output that were of similar order of magnitude in both the United States and the EU.

In the econometric analysis of short-term fluctuations, it is difficult to separate the impact of the aggregate shock created by the pandemic from that of the NPI measures taken by national governments in the EU and individual American states. Our estimates suggest that the dynamic of unemployment rates appears to be driven mostly by the economic shock affecting supply and demand in the United States and the European Union (Smith, 2020). We find little difference in these results between female and male unemployment.

We realise that focusing on the unemployment rate is not sufficient. It would be enlightening to analyse the effects of NPIs on additional labour market statistics to understand better their full impact on labour outcomes. However, this can only be done when the relevant data become available. 


\section{References}

Alon, T., M. Doepke, J. Olmstead-Rumsey and M. Tertilt (2020), The Impact of COVID-19 on Gender Equality, Working Paper No. 26947, National Bureau of Economic Research, Cambridge, Mass., April.

Amuedo-Dorantes, C., M. Marcen, M. Morales and A. Sevilla (2020), COVID-19 School Closures and Parental Labor Supply in the United States, IZA Discussion Paper No. 13827, IZA Institute of Labor Economics, Bonn, October.

Barlevy, G. (2002), "The sullying effect of recessions", The Review of Economic Studies, vol. 69, no. 1, pp. 65-96.

Barrero, J. M., N. Bloom and S. J. Davis (2020), Covid-19 Is Also a Reallocation Shock, Working Paper No. 27137, National Bureau of Economic Research, Cambridge, Mass., May.

Brodeur, A., D. M. Gray, A. Islam and S. Bhuiyan (2020), A Literature Review of the Economics of COVID-19, IZA Discussion Paper No. 13411, IZA - Institute of Labor Economics, Bonn, June.

Caballero, R. J. and M. L. Hammour (1994), "The cleansing effect of recessions", The American Economic Review, vol. 84, no. 5, pp. 1350-68.

Cahuc, P. (2019), Short-time Work Compensation Schemes and Employment, IZA - Institute of Labor Economics, Bonn.

Chen, S., D. O. Igan, N. Pierri and A. F. Presbitero (2020), Tracking the Economic Impact of COVID-19 and Mitigation Policies in Europe and the United States, IMF Working Paper No. 20/125, International Monetary Fund, Washington, D.C., 10 July.

Chodorow-Reich, G. and J. Coglianese (2020), Projecting Unemployment Durations: A FactorFlows Simulation Approach with Application to the COVID-19 Recession, Working Paper No. 27566, National Bureau of Economic Research, Cambridge, Mass., July.

Cowan, B. W. (2020), Short-run Effects of COVID-19 on U.S. Worker Transitions, Working Paper No. 27315, National Bureau of Economic Research, Cambridge, Mass., June.

Dreger, C., and D. Gros (2021), Lockdowns and the US Unemployment Crisis, IZA Policy Paper Np. 170, IZA - Institute of Labor Economics, Bonn, January.

Fana, M., S. Tolan, S. Torrejón, C. Urzi Brancati and E. Fernández-Macías (2020), The COVID Confinement Measures and EU Labour Markets, JRC Technical Reports, Joint Research Centre, European Commission, Publications Office of the European Union, Luxembourg.

Fernández-Villaverde, J. and C. I. Jones (2020), Macroeconomic Outcomes and COVID-19: A Progress Report, Working Paper No. 28004, National Bureau of Economic Research, Cambridge, Mass., October. 
Forsythe, E., L. B., Kahn, F. Lange and D. G. Wiczer (2020), Labor Demand in the Time of COVID19: Evidence from Vacancy Postings and UI Claims, Working Paper No. 27061, National Bureau of Economic Research, Cambridge, Mass., April.

Forsythe, E., L. B. Kahn, F. Lange and D. G. Wiczer (2020), Searching, Recalls, and Tightness: An Interim Report on the COVID Labor Market, Working Paper No. 28083, National Bureau of Economic Research, Cambridge, Mass., December.

Gallant, J., K. Kroft, F. Lange and M. J. Notowidigdo (2020), Temporary Unemployment and Labor Market Dynamics during the COVID-19 Recession, Working Paper No. 27924, National Bureau of Economic Research, Cambridge, Mass., October.

Gezici, A. and O. Ozay (2020), How Race and Gender Shape COVID-19 Unemployment Probability, Working Paper Series No. 521, Political Economy Research Institute, University of Massachusetts Amherst, August.

Gupta, S., L. Montenovo, T. D. Nguyen et al. (2020), Effects of Social Distancing Policy on Labor Market Outcomes, Working Paper No. 27280, National Bureau of Economic Research, Cambridge, Mass., May.

Hale, T., J. Anania, N. Angrist, et al. (2021), Variation in Government Responses to COVID-19, BSG Working Paper Series No. BSG-WP-2020/32, Blavatnik School of Government, Oxford University, March.

Juranek, S., J. Paetzold, H. Winner and F. T. Zoutman (2020), Labor Market Effects of COVID-19 in Sweden and Its Neighbors: Evidence from Novel Administrative Data, Discussion Paper No. 2020/8, Department of Business and Management Science, Norwegian School of Economics (NHH).

Kong, E. and D. Prinz (2020), "Disentangling policy effects using proxy data: Which shutdown policies affected unemployment during the COVID-19 pandemic?" Journal of Public Economics, vol. 189, p. 104257.

Lozano Rojas, F., X. Jiang, L. Montenovo, K. I. Simon, B. A. Weinberg and C. Wing (2020), Is the Cure Worse than the Problem Itself? Immediate Labor Market Effects of COVID-19 Case Rates and School Closures in the U.S., Working Paper No. 27127, National Bureau of Economic Research, Cambridge, Mass., May.

Montenovo, L., X. Jiang, F. Lozano Rojas et al. (2020), Determinants of Disparities in COVID-19 Job Losses, Working Paper No. 27132, National Bureau of Economic Research, Cambridge, Mass., December.

Reichelt, M., K. Makovi and A. Sargsyan (2020), "The impact of COVID-19 on gender inequality in the labor market and gender-role attitudes", European Societies, vol. 23, no. 5, pp. 1-18.

Smith, C. (2020), Understanding supply and demand shocks amid Coronavirus, Federal Reserve Bank of St Louis Open Vault Blog. 


\section{Appendix A. Oxford Indices and the Stringency Index}

Each subcategory takes a discrete number between 0 and the maximum value displayed in Table 1. For instance, the following coding ${ }^{10}$ applies to school closings:

$$
\begin{aligned}
& 0 \text { - No measures } \\
& 1 \text { - Recommended closing } \\
& 2 \text { - Require closing (only some levels or categories) } \\
& 3 \text { - Require closing all levels }
\end{aligned}
$$

Therefore, a high value for any subcategories implies a stricter policy. To account for different maximum values across subcategories, we follow Hale et al. (2020) and compute indices for each of the nine subcategories $K_{i} \in\{C 1, C 2, \ldots, H 1\}$ :

$$
I_{i}=\frac{K_{i}-0.5\left(1-K_{i, \mathrm{flag}}\right)}{\max \left(K_{i}\right)}
$$

where $K_{i, f l a g}$ is a flag variable for subcategory $K_{i}$, which takes on the value 1 when the policy is enforced at national level. In the case of schooling, a recommended closing at local/regional level is assigned the value 0.5 instead of 1 for the same policy at national

level.

International travel controls (C8) do not feature any flag variable, and the above formula simplifies to:

$$
I_{8}=\frac{K_{8}}{\max \left(K_{8}\right)}
$$

By construction, these nine indices take values between 0 and 1 and are then averaged to create a stringency index ${ }^{11}$ :

$$
S T R_{O X}=\sum_{i=1}^{9} \frac{I_{i}}{9}
$$

\footnotetext{
10 The codebook for the remaining subcategories is available through the following link.

${ }^{11}$ Oxford's indices take values between 0 and 100 . See methodology.
} 
Appendix B. Regression results

Table 2

\begin{tabular}{|c|c|c|c|c|c|c|c|c|}
\hline \multirow[b]{2}{*}{ Index } & \multicolumn{4}{|c|}{ U.S. } & \multicolumn{3}{|c|}{ E.U. } & \multirow[b]{2}{*}{$R^{2}$} \\
\hline & $\hat{\delta}_{0}$ & $\hat{\delta}_{1}$ & $\hat{\delta}_{2}$ & $R^{2}$ & $\hat{\delta}_{1}$ & $\hat{\delta}_{1}$ & $\hat{\delta}_{2}$ & \\
\hline$\Delta I 1$ & $\begin{array}{l}2.17^{*} \\
(1.119)\end{array}$ & $\begin{array}{l}-0.04 \\
(1.166)\end{array}$ & $\begin{array}{l}-0.36 \\
(1.179)\end{array}$ & 0.792 & $\begin{array}{l}0.53^{*} \\
(0.288)\end{array}$ & $\begin{array}{c}-0.04 \\
(0.369)\end{array}$ & $\begin{array}{l}-0.26 \\
(0.288)\end{array}$ & 0.283 \\
\hline$\Delta I 2$ & $\begin{array}{l}-0.08 \\
(0.696)\end{array}$ & $\begin{array}{l}0.95 \\
(0.731)\end{array}$ & $\begin{array}{l}-0.49 \\
(0.647)\end{array}$ & 0.790 & $\begin{array}{l}0.17 \\
(0.218)\end{array}$ & $\begin{array}{l}-0.59^{* *} \\
(0.277)\end{array}$ & $\begin{array}{l}-0.46 \\
(0.351)\end{array}$ & 0.309 \\
\hline$\Delta I 3$ & $\begin{array}{l}0.03 \\
(0.650)\end{array}$ & $\begin{array}{l}-0.02 \\
(0.627)\end{array}$ & $\begin{array}{l}0.63 \\
(0.545)\end{array}$ & 0.789 & $\begin{array}{l}0.35^{* *} \\
(0.145)\end{array}$ & $\begin{array}{l}-0.09 \\
(0.157)\end{array}$ & $\begin{array}{l}0.00 \\
(0.161)\end{array}$ & 0.277 \\
\hline$\Delta I 4$ & $\begin{array}{l}0.15 \\
(0.766)\end{array}$ & $\begin{array}{l}-1.03 \\
(0.690)\end{array}$ & $\begin{array}{l}0.71 \\
(0.641)\end{array}$ & 0.791 & $\begin{array}{l}0.01 \\
(0.243)\end{array}$ & $\begin{array}{l}-0.09 \\
(0.255)\end{array}$ & $\begin{array}{l}-0.16 \\
(0.218)\end{array}$ & 0.262 \\
\hline$\Delta I 5$ & $\begin{array}{l}-2.24^{*} \\
(1.147)\end{array}$ & $\begin{array}{l}-0.59 \\
(0.721)\end{array}$ & $\begin{array}{l}0.81 \\
(0.933)\end{array}$ & 0.795 & $\begin{array}{l}-0.05 \\
(0.292)\end{array}$ & $\begin{array}{l}0.11 \\
(0.197)\end{array}$ & $\begin{array}{l}0.24 \\
(0.195)\end{array}$ & 0.266 \\
\hline$\Delta I 6$ & $\begin{array}{l}0.82 \\
(1.107)\end{array}$ & $\begin{array}{l}0.15 \\
(0.988)\end{array}$ & $\begin{array}{l}-0.14 \\
(0.805)\end{array}$ & 0.789 & $\begin{array}{l}0.07 \\
(0.276)\end{array}$ & $\begin{array}{l}-0.45^{*} \\
(0.273)\end{array}$ & $\begin{array}{l}-0.20 \\
(0.275)\end{array}$ & 0.273 \\
\hline$\Delta I 7$ & $\begin{array}{l}0.44 \\
(0.649)\end{array}$ & $\begin{array}{l}0.84 \\
(0.512)\end{array}$ & $\begin{array}{l}-0.36 \\
(0.435)\end{array}$ & 0.791 & $\begin{array}{l}-0.03 \\
(0.185)\end{array}$ & $\begin{array}{l}-0.13 \\
(0.152)\end{array}$ & $\begin{array}{l}-0.08 \\
(0.147)\end{array}$ & 0.263 \\
\hline$\Delta I 8$ & $\begin{array}{l}-0.20 \\
(1.238)\end{array}$ & $\begin{array}{l}-0.36 \\
(1.037)\end{array}$ & $\begin{array}{l}-0.16 \\
(1.349)\end{array}$ & 0.789 & $\begin{array}{l}0.16 \\
(0.227)\end{array}$ & $\begin{array}{l}0.09 \\
(0.278)\end{array}$ & $\begin{array}{l}-0.13 \\
(0.274)\end{array}$ & 0.264 \\
\hline$\Delta I 9$ & $\begin{array}{l}0.28 \\
(0.513)\end{array}$ & $\begin{array}{l}-0.25 \\
(0.878)\end{array}$ & $\begin{array}{l}0.43 \\
(0.741)\end{array}$ & 0.789 & $\begin{array}{l}0.02 \\
(0.167)\end{array}$ & $\begin{array}{l}0.42 \\
(0.266)\end{array}$ & $\begin{array}{l}-0.22 \\
(0.251)\end{array}$ & 0.288 \\
\hline$\Delta S T R_{O X}$ & $\begin{array}{l}0.57 \\
(1.656)\end{array}$ & $\begin{array}{l}-0.26 \\
(1.618)\end{array}$ & $\begin{array}{l}0.82 \\
(1.431)\end{array}$ & 0.789 & $\begin{array}{l}0.43 \\
(0.528)\end{array}$ & $\begin{array}{l}-0.28 \\
(0.455)\end{array}$ & $\begin{array}{l}-0.57 \\
(0.480)\end{array}$ & 0.274 \\
\hline
\end{tabular}

Each row corresponds to a specific regression. The first three columns display the estimated coefficients for Index $I_{j}$ (current value, first lag and second lag respectively). Heteroskedastic robust standard errors are given in parenthesis. Stars indicate statistical significance at $10 \%, 5 \%$ and $1 \%$ levels. The fourth column shows the $R^{2}$ from the regression. 